\title{
The Wheels on the Bot go Round and Round: Robotics Curriculum in Pre-Kindergarten
}

\author{
Amanda Sullivan, Elizabeth R. Kazakoff, \\ and Marina Umashi Bers \\ Tufts University, Medford, Massachusetts, USA
}

\author{
Amanda.Sullivan@tufts.edu; Elizabeth.Kazakoff@tufts.edu; \\ Marina.Bers@tufts.edu
}

\section{Executive Summary}

This paper qualitatively examines the implementation of an intensive weeklong robotics curriculum in three Pre-Kindergarten classrooms $(\mathrm{N}=37)$ at an early childhood STEM (science, technology, engineering, and math) focused magnet school in the Harlem area of New York City. Children at the school spent one week participating in computer programming activities using a developmentally appropriate tangible programming language called CHERP, which is specifically designed to program a robot's behaviors. The children used CHERP to program "Robot Recyclers" that they constructed using parts from LEGO ${ }^{\mathbb{R}}$ Education WeDo ${ }^{\mathrm{TM}}$ Robotics Construction Sets. The Robot Recyclers were designed to help carry, push, and/or sort recyclable materials found in the classroom. Researchers were participant-observers in the robotics lessons over the course of curriculum implementation. Each lesson was taught by the researchers, with classroom teachers present in order to facilitate classroom management and assist with small group work. A combination of interviews, video, photographs, and classroom observations were used to document the students' experiences. Classroom teachers were also interviewed and asked to complete anonymous pre and post surveys. Results from this study provide preliminary evidence that PreKindergarten children can design, build, and program a robot after just one week of concentrated robotics work. Additionally, results indicate that teachers were able to successfully integrate robotics work into their classrooms that included foundational math and literacy concepts while also engaging children in the arts. However, this study also highlights the difficulties and challenges that must be considered before implementing a robotics curriculum into a PreKindergarten classroom, including opportunities for one-to-one adult assistance during building and programming activities.

Keywords: computer programming, Pre-Kindergarten, robotics, early childhood education, STEM

\begin{abstract}
Material published as part of this publication, either online or in print, is copyrighted by the Informing Science Institute. Permission to make digital or paper copy of part or all of these works for personal or classroom use is granted without fee provided that the copies are not made or distributed for profit or commercial advantage AND that copies 1) bear this notice in full and 2) give the full citation on the first page. It is permissible to abstract these works so long as credit is given. To copy in all other cases or to republish or to post on a server or to redistribute to lists requires specific permission and payment of a fee. Contact Publisher@InformingScience.org to request redistribution permission.
\end{abstract}

\section{Introduction}

As our world becomes increasingly digital, new initiatives and policies are in place with the goal of bringing STEM (science, technology, engineering, and math) education to the early grades (see Barron et. al., 2011; ISTE, 2007; National Association for the Education of Young Children \& Fred Rogers Center 
2012; U.S. Department of Education, 2010a, 2010b). While the majority of research on robotics and programming in education focuses on later schooling, teaching these subjects during foundational early childhood years can be an engaging and rewarding experience for young learners (Bers, 2008). Previous research suggests that children as young as four years old can build and program simple robotics projects (Bers, Ponte, Juelich, Viera, \& Schenker, 2002; Cejka, Rogers, \& Portsmore, 2006; Perlman, 1976; Wyeth, 2008). Robotic manipulatives allow children to develop fine motor skills and hand-eye coordination while also engaging in collaboration and teamwork. Prior research demonstrates that kindergarteners can successfully learn powerful ideas of engineering, technology, and computer programming while also building their computational thinking skills (Bers, 2010; Kazakoff \& Bers, 2012; Sullivan \& Bers, 2012). However, very little research has been done on the use of robotics and computer programming in Pre-Kindergarten classrooms.

New York State, the location of the school where this pilot study took place, aims to align its curriculum with the Common Core Standards. The Common Core Standards are a single set of educational standards for Kindergarten through 12th grade that states voluntarily adopt. Currently, forty-five states have adopted the Common Core Standards. Within these standards for PreKindergarten, there are several benchmarks for technology education that can be found in the New York State Pre-Kindergarten Foundation for the Common Core (NYSED, 2011). According to these standards, Pre-Kindergarten children should be able to do the following: 1) understand how technology affects them in daily life, and how it can be used to solve problems, 2) how to use computers for writing, drawing, and exploration, and 3) how to use technological tools independently (NYSED, 2011).

In light of these Common Core Standards, the purpose of this study is to qualitatively examine how an intensive robotics curriculum is implemented in three Pre-Kindergarten classrooms at a STEM-focused magnet school and describe how this curriculum was implemented in a developmentally appropriate way. The goal of this paper is to describe the feasibility of implementing a 10-hour robotics curriculum in Pre-Kindergarten by detailing the curriculum, the implementation procedures, the learning outcomes from students, and the thoughts of classroom teachers. This exploratory study adds to the budding research base regarding technology and engineering in early childhood education.

\section{Developmental Considerations}

Children in Pre-Kindergarten, according to Piagetian theory, are within the preoperational stage, characterized by learning about symbolic representation. Children learn through assimilation and accommodation. Assimilation is taking information in to fit ideas or knowledge structures that already exist. Accommodation is when children alter their understanding based on new information (Piaget, 1977; Siegler, 1998). Assimilation and accommodation work with each other as a child learns a new concept: in the case of this study, the concept of "robot" or "engineer".

Vygotsky (1978), building on Piaget's work, emphasized the social context of the child. One of Vygotsky's most well-known concepts, the zone of proximal development, describes how children can achieve goals with the help of teachers and peers, which they would not otherwise be able to achieve on their own. Vygotsky's theories around the influence of social context, particularly now with children's exposure to digital technologies, are influential when developing curriculum that aims to bridge real world and classroom experiences. In addition, opportunities for social interactions, collaboration, and scaffolding are planned directly into early childhood curriculum, such as the one used in this study.

Some contemporary research on STEM education in Pre-Kindergarten focuses on how technology may be used as a manipulative. For example, computer-mediated curriculum, like the Build- 
ing Blocks curriculum for math, uses digital manipulatives, putting everyday problems on the screen for young children to solve (Clements, 2002). The curriculum used in the current study also uses on screen and physical manipulatives to aid children in solving their own contextualized challenges (e.g., making a robot recycle).

For young children who are in a developmental process of learning how to work with others, the design features of certain types of technology can promote social and pro-social development (Bers, 2012). Early work with technology and young children has shown that computers can serve as catalysts for social interaction in early childhood education classrooms (Clements, 1999) and that children have twice as many verbal interactions in front of the computer than when they are doing other activities, such as solving puzzles (Svensson, 2000). Children are also more likely to go to their peers for help when using the computer, even when an adult is present, thus increasing the amount of peer collaboration in the classroom (Wartella \& Jennings, 2000).

\section{Robotics in Pre-Kindergarten}

Robotics was chosen as a domain for several reasons. As a tool, it can help make abstract ideas more concrete, as the child can directly view the impact of his or her programming commands on the robot's actions. Children who work with robotics are not sitting in front of a computer, but are engaged in developing fine motor skills while manipulating the robotic objects. They can move around the room, work on the floor or table, and act out, with their own bodies, the programming sequences the robots will follow. Robotics becomes the new early childhood manipulative of the $21^{\text {st }}$ Century (Bers, 2008). New technologies, in general, and robotics, in particular, make different kinds of learning opportunities possible, including new ways to foster peer social interactions, and many opportunities for creativity, social, and cognitive development. Educational robotic kits are a new generation of learning manipulatives that also help children develop a stronger understanding of mathematical concepts such as number, size, and shape in much the same way that traditional materials like pattern blocks, beads, and balls do (Brosterman, 1997).

While there are a host of robotic kits and programming languages designed for older children (e.g., LEGOTM Mindstorms), in early elementary school there are a limited number of robotics tools available, and many focus on social interaction rather than on programming (e.g., Keepon, Tofu, Mocchi) (Kozima, Michalowski, \& Nakagawa, 2009; Stiehl, Chang, Wistort, \& Breazeal, 2009 ). For teaching young children to control the actions of robots, schools primarily use BeeBots and ProBots. Beebots and Probots are commercially available robotic toys developed by Terrapin Thinking Tools (http://www.terrapinlogo.com ). The Beebot (a colorful robot designed to resemble a bee) contains keys that are used to enter up to 40 different commands. By using these commands, children can send the Bee-Bot forward, back, left, and right. Similarly, the ProBot (a colorful robot that resembles a car) was developed by the same makers of the Bee-Bot and allows for more advanced control techniques and the use of sensors.

The development of these types of robotic toys for young children falls in line with research that has shown young children are able to understand robotic rules and create commands for robots to follow (Mioduser \& Levy, 2010). As mentioned, research has demonstrated that children as young as four years old can build and program simple robots and that there are many benefits of integrating robotic technologies into the early childhood classroom in developmentally appropriate ways (Bers, 2008, 2010; Bers et. al., 2002; Kazakoff \& Bers, 2012; Kazakoff, Sullivan, \& Bers, 2013; Rogers \& Portsmore, 2004). In addition to learning to program, Beebots and Probots specifically have been used to teach math concepts in preschool (Highfield, 2010).

Both from an economic and a developmental standpoint, educational interventions that begin in early childhood are associated with lower costs and longer-lasting effects than interventions that begin later in childhood (Cuhna \& Heckman, 2007; Reynolds, Temple, Ou, Arteaga, \& White, 
2011). In addition, preliminary research suggests that children who are exposed to STEM curriculum and computer programming at an early age demonstrate fewer gender-based stereotypes regarding STEM careers (Metz, 2007; Steele, 1997) and fewer obstacles entering these fields (Madill et al., 2007; Markert, 1996).

Some aspects of engineering are very commonly seen in early childhood classrooms. For example, it is common to see young children using recycled materials or Lego bricks to build cities and bridges. However, what is unique to our human-made world today is the fusion of electronics with mechanical structures. Through robotics education, young children can become engineers by playing with gears, levers, motors, sensors, as well as storytellers by creating their own meaningful projects that react in response to their environment (Bers, 2008).

Robotics was chosen for this study because of the power of robotics as a tool that spans the science, technology, engineering, and math fields. Primarily, robotics encompasses the electronic aspects of engineering that is often missing in early childhood education.

\section{Computer Programming in Early Childhood Education}

One of the first programming languages for children, LOGO, was designed by Seymour Papert (1980) with the goal of helping children learn mathematics in a new way and enhance problemsolving skills. Continued research showed that mediated use of LOGO, the use of the programming language in context, with instruction by teachers and feedback on performance, with a goal of building transferable skills, actually demonstrated the most educational value (Siegler, 1998). Reviews of early studies, particularly using LOGO, have demonstrated using computers likely impacts young children's higher-order thinking skills, such as theory of mind, problem solving, self-monitoring, and metacognition (Clements, 2002).

Recent research and theories based on new programming environments support the argument that children's programming of animations, graphical models, games, and robots (with ageappropriate materials) allows them to learn and apply concepts such as abstraction, automation, analysis, decomposition, and iterative design (e.g., Lee et al., 2011; Mioduser \& Levy 2010; Resnick, 2006; Resnick et. al., 2009).

When children program robots, they are engaged in sequencing the commands that comprise a robot's program (Kazakoff \& Bers, 2012; Kazakoff et al., 2013). Sequencing is an important early childhood skill found in both curricular frameworks and, subsequently, in many learning assessments. Sequencing is a component of planning and involves putting objects or actions in the correct order (Zelazo, Carter, Reznick, \& Frye, 1997). For example, retelling a story in a logical sequence, ordering numbers in the correct sequence, and understanding the sequence of a day's activities are all sequencing activities represented in curriculum frameworks for kindergarten through second grade in both language arts and mathematics (Engage NY, 2011; MA DOE, 2011a, 2011b). Sequencing, along with sorting, measurement, and pattern recognition are a child's mathematical building blocks; starting with these foundational skills, children begin to think of the world mathematically (Sarama \& Clements, 2003). Prior research with the robotics and programming curriculum used in this study has shown repeated, significant improvements in sequencing skills for children in kindergarten classrooms (Kazakoff \& Bers, 2012; Kazakoff et al., 2013).

\section{Programming with CHERP}

The programming software used in this study is called CHERP (Creative Hybrid Environment for Robotic Programming). CHERP is a hybrid tangible and graphical computer language designed with funding from the National Science Foundation to provide young children with an engaging and developmentally appropriate introduction to computer programming. CHERP allows children 
to create both physical/tangible and graphical/on-screen programs to control their robots (Bers \& Horn, 2010). Children can create physical programs using interlocking wooden blocks or onscreen programs using the same icons that represent actions for a robot to perform (Figure 1). Informed by the spirit of puzzles, there is no such thing as a syntax error. With CHERP, the shape of the interlocking blocks and icons creates a physical syntax that prevents the creation of invalid programs. CHERP programs can be compiled in a matter of seconds with the press of a button.

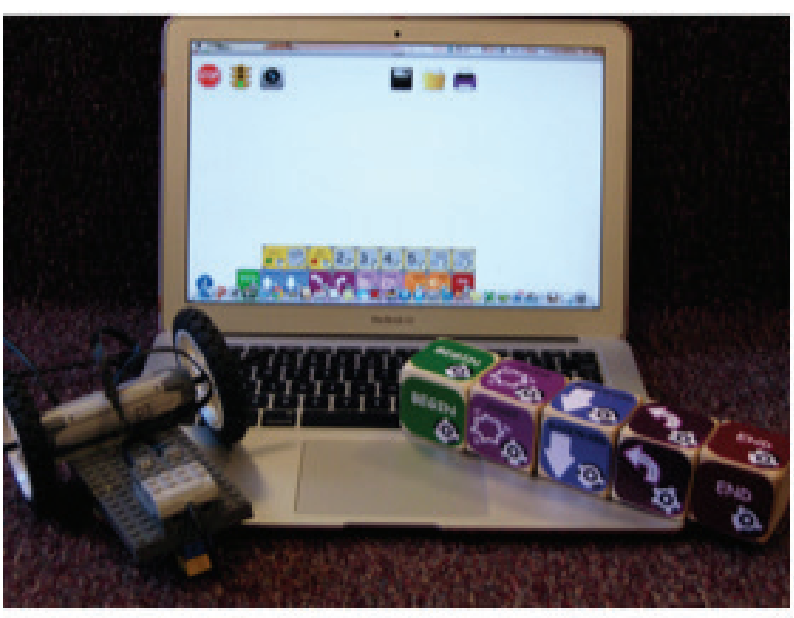

Figure 1: CHERP Computer Programming Software
CHERP uses a collection of imageprocessing techniques to convert physical programs into digital instructions. Each block in the language is imprinted with a circular symbol called "TopCode" (http://users.eecs.northwestern.edu/ mhor n/topcodes ). These codes allow the position, orientation, size, shape, and type of each statement to be quickly determined from a digital image. A standard webcam can be connected to a desktop or laptop computer to take a picture of the program, or a laptop's internal webcam can be used. A compiler converts the picture into digital code that is downloaded and transmitted to the $\mathrm{WeDo}^{\mathrm{TM}}$ robot through the $\mathrm{LEGO}^{\circledR} \mathrm{WeDo}^{\mathrm{TM}}$ USB hub.

\section{Robotics Curriculum in Early Childhood}

The curriculum implemented during this study was designed according to the Positive Technological Development Framework (PTD). The PTD framework is an extension of the computer literacy and the technological fluency movements that have influenced the world of educational technology but adds psychosocial and ethical components to the cognitive ones (Bers, 2006, 2008, 2010, 2012). PTD takes into consideration the learning environment, pedagogical practices, as well as cultural values and rituals that mediate teaching and learning (Rogoff, 2003; Rogoff, Goodman, Turkanis \& Bartlett, 2001). A curriculum designed following the PTD framework, such as the one presented in this paper, provides a learning experience in which children can use robotics as a medium to develop a sense of competence and confidence in their technological skills and their creativity in developing projects from idea to final implementation to sharing them with a community. Among the skills that the PTD framework fosters are social interaction skills such as communication, collaboration, and choices of conduct.

The robotics curriculum used in this study was integrated with a larger, exploratory unit on tools that the Pre-Kindergarten classes were already completing as part of their standard curriculum. The curriculum involved approximately 10 hours of work over the course of 5 days. Implementation of this study coincided with the school's "Robotics Week," an intensive school-wide experience where all classes are immersed in robotics, computer programming, and engineering for one week. During this time, the Pre-Kindergarten students in this study spent the week focused on designing, building, and programming robotic tools that can assist with the recycling process.

\section{The Engineering Design Process}

The Engineering Design process was a central aspect of the robotics curriculum implemented in this study. When working with young children and robotics, teachers may encounter problems scaffolding the child's problem-solving processes (Bers, 2008). Understanding and applying the 
Engineering Design Process (Figure 2) is a useful tool for children to manage their frustrations and continue working on a given programming or building task without giving up (Bers, 2008). The Engineering Design Process is a cyclical process used by real-world engineers. Its steps include identifying a problem, looking for ideas, developing, testing and improving solutions, and sharing solutions with others. In the classroom, the Engineering Design Process places emphasis on continually changing and refining the child's work rather than achieving "the right answer" at the start. This idea of constantly testing and improving your work based on feedback and help from your peers lines up with the skills of communication and collaboration fostered by the PTD framework.

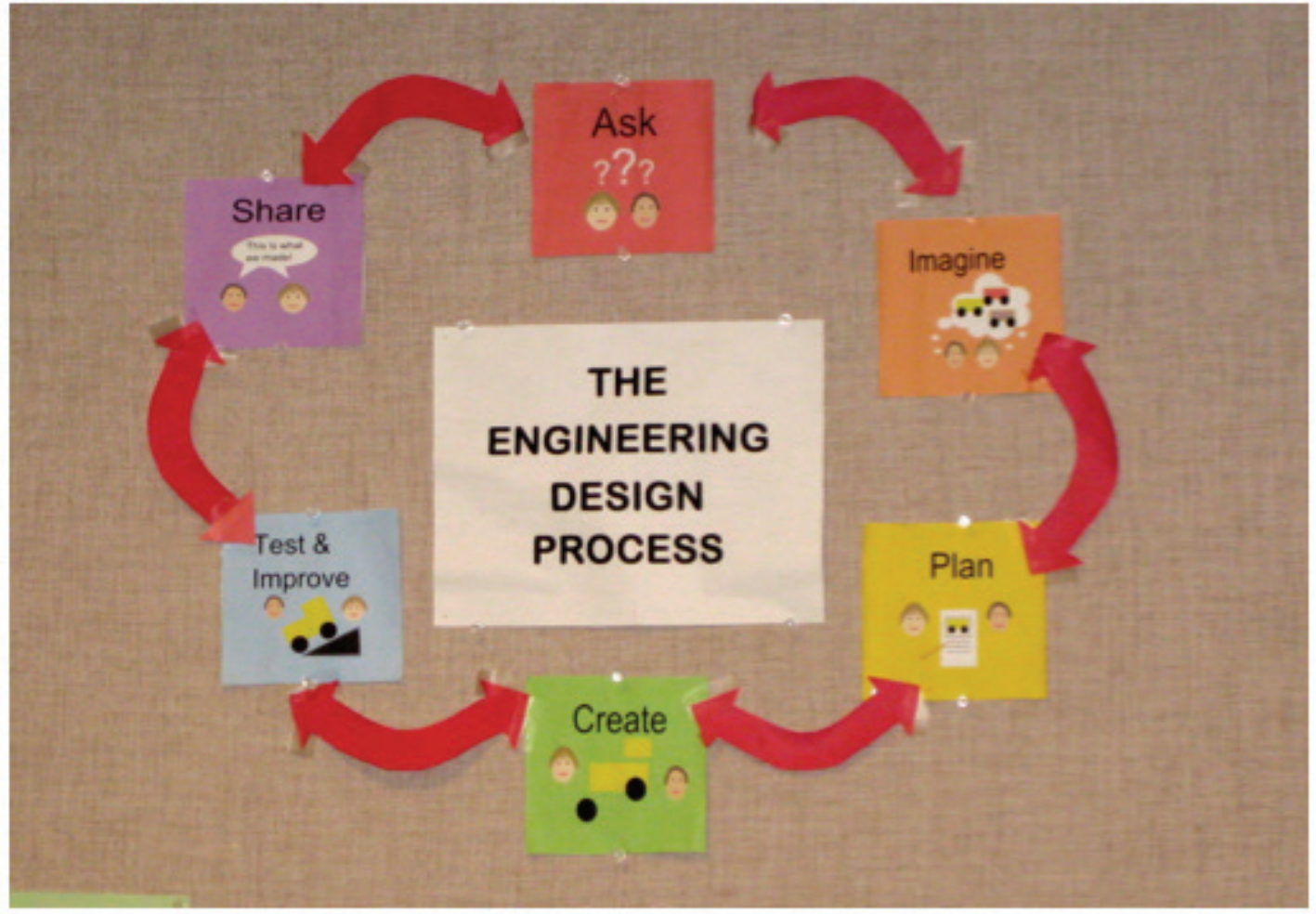

Figure 2: The Engineering Design Process

\section{Robotics Hardware}

The LEGO ${ }^{\circledR}$ Education WeDo ${ }^{\mathrm{TM}}$ Robotics Construction Set is a robotics kit that allows children to build $\mathrm{LEGO}^{\circledR}$ robots that feature working motors and sensors. The construction sets contain more than 150 elements including a motor, tilt sensor, motion sensor, a LEGO ${ }^{\circledR}$ USB hub, gears, and a variety of LEGO $^{\circledR}$ bricks. Students also used LEGO ${ }^{\circledR}$ wheels (not included in the kit) to build their robots (Figure 3 ).

Once a robot is built, a tangible program can be uploaded to it by placing the program in the web camera's field of view and connecting the robot

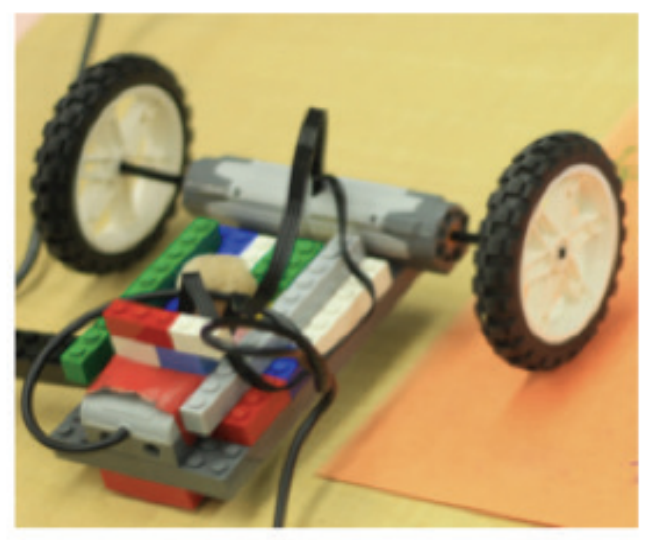

Figure 3: Child-Made LEGO® WeDO ${ }^{\text {TM }}$ Robot 
to the computer using the USB hub. The computer takes a photo to "see" the blocks, and then the program is visible on-screen and is sent to the robot. To upload from the graphical icons onscreen, children click and drag the programming icons together. Like the tangible blocks, they will only "snap together" when they are close enough and can make a logical sequence.

\section{Method}

Qualitative data collection measures were employed to examine the pilot implementation of an intensive robotics curriculum in three Pre-Kindergarten classrooms $(\mathrm{N}=37)$ at an early childhood STEM magnet school. In addition to studying the child participants, the three Pre-Kindergarten teachers from each of the participating classrooms also completed surveys reflecting on the experience.

\section{Participants}

Participants in this study were 37 Pre-Kindergarten students attending a public, early childhood magnet school in the Harlem area of New York City. These 37 students come from all three PreKindergarten classrooms at the school. While all 55 enrolled Pre-Kindergarten students were invited to participate, these 37 children represent those that returned signed consent forms from their parents $(67.3 \%$ consent rate). These students were identified by their parent/guardian as members of the following groups: 50\% African American, 12.5\% Hispanic, 6.3\% Mixed Race, $3.1 \%$ Caucasian, and 3.1\% West Indian. The remaining $25 \%$ of students were identified as either "other" or their parent/guardian chose not to answer. At the time of the study (near the end of the school year) all participating children were 5 years old. A fairly even number of male and female students participated (approximately 54\% male and 46\% female).

In addition to the children sampled, the three Pre-Kindergarten teachers from the school also participated in this study by completing pre and post surveys regarding their perception of student knowledge and mastery of concepts being taught. All teachers were female and had over 20 years of teaching experience (an average of 23.3 years).

\section{Procedure}

Researchers were participant-observers in robotics lessons over the course of a five-day introductory robotics curriculum being implemented at the school. Each lesson was taught by the researchers, with classroom teachers present in order to facilitate classroom management and assist with small group work. A combination of formal and informal interviews, video, photographs, and classroom observations were used to document the students' experiences. Classroom teachers were interviewed and asked to complete anonymous pre and post surveys. This paper will focus on presenting data from the interviews, questionnaires, and observations described below.

\section{Interviews}

Due to the busy public school environment and limited time available during curriculum implementation, researchers were not able to individually interview all 37 participating PreKindergarten students. Subsets of approximately eight children were selected from each PreKindergarten classroom by their teacher. This selection was based on the child's schedule and their willingness to participate. The selected students participated in formal interviews at the beginning and end of Robotics Week. Children were asked to describe their thoughts on the definition of the words "engineer" and "robot". The children were also asked if they were familiar with the Engineering Design Process (this was the main concept taught during the robotics week) and to list as many of the steps of the Engineering Design Process as they could. 


\section{Teacher Surveys}

Each of the three Pre-Kindergarten classroom teachers completed an anonymous pre-survey before Robotics Week and an anonymous post-survey upon completion of the week addressing their conceptions of teaching and learning through robotics through a combination of Likert-scale and free-response questions. The post-survey specifically asked questions about how much they thought their students learned about robotics and computer programming. The post-survey also asked teachers to reflect on how well math and literacy were integrated into the robotics curriculum.

\section{Classroom observations}

During class sessions, the researchers conducted unstructured observations while implementing the robotics curriculum. Due to the researcher's dual role in the classroom (to observe as well as teach a curriculum) the unstructured approach was chosen over a structured or semi-structured approach in order to allow the researchers flexibility to divide their attention and deal with any classroom issues. Researchers paid particular attention to student behaviors, problem-solving strategies, social interactions, and their expression of ideas related to robotics, computer programming, and engineering. Additionally, researchers recorded notes on the robotics final projects created and programmed by the students. Observations were recorded in the form of written field notes during and after class sessions.

\section{Robotics Program Overview}

\section{Curriculum}

The robotics curriculum involved approximately 10 hours of intensive work over the course of 5 days (approximately 2 hours per day). Implementation of this curriculum coincided with the school's "Robotics Week," an intensive weeklong experience where all classes are immersed in robotics, computer programming, and engineering. Prior to this week, the Pre-Kindergarten students completed an introductory unit on tools. Throughout this unit, children became familiar with to concept of tools and investigated the use of common tools around the house, garden, and school. The robotics curriculum was designed to serve as the culmination to this unit on tools. Students spent the week focused on tools that can assist with the recycling process. Children designed these tools by engaging in the engineering design process, built them using the robotic kits, and programmed their behaviors using the programming language associated with the kit. After developing proficiency in several core areas of engineering, robotics, and computer pro-

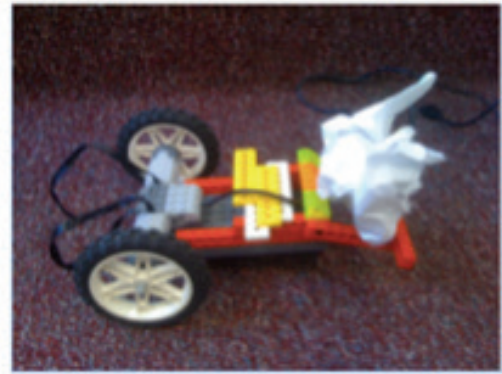

Figure 4: Sample Robot Recycler gramming during the first half of the week, children worked in small groups to build and program "Robot Recyclers" (Figure 4) to help carry, push, and/or sort recyclable materials found in the classroom, aligning with the state curriculum framework of "expresses an understanding of how technology affects them in daily life, and how it can be used to solve problems" (NYSED, 2011, p. 37). Robotics Week culminated in a school-wide Open House, to which parents, siblings, and students from a neighboring school were invited to attend. The Pre-Kindergarten students demonstrated their Robot Recyclers for this open house and also explained to guests what recycling is and how their robots can help. 
The core concepts covered during the unit were broken up into the following activities:

- Activity 1: What is the Engineering Design Process \& What are Engineers?

Students were introduced to what an engineer is and how to use the engineering design process (see "the Engineering Design Process Song" in the Appendix). Children learned about different types of engineers and played games that allowed them to identify structures designed and made by engineers (versus naturally occurring structures and living things). They used LEGO ${ }^{\circledR}$ and art materials - all non-robotic materials - to build a sturdy model of a real-world tool they had been studying. The powerful idea in Lesson 1 (building sturdily through use of the Engineering Design Process) is critical to the success of the children's robots in later lessons and was revisited throughout the week.

\section{- Activity 2: What is a Robot?}

Students shared and learned ideas about what robots are. They were introduced to LEGO ${ }^{\circledR}$ WeDo ${ }^{\mathrm{TM}}$ robotics concepts (see "the Robot Parts Song" in the Appendix). Children built and tested their own robotic vehicles.

\section{- Activity 3: What is a Program?}

Students learned about programming and were introduced to the various CHERP programming commands. Students programmed their robots to help push crumpled paper.

\section{- Culminating Project: Robot Recyclers}

Students spent the remainder of the week (Wednesday-Friday) modifying their robots or building from scratch to create a "Robot Recycler". Students programmed these robots to perform a function related to recycling in the classroom (i.e., pushing, carrying, or sorting paper or other materials). Students were allowed to freely explore and test out sample programs with the end goal of having a functioning recycler by the end of the week.

In addition to these engineering concepts, each lesson integrated foundational concepts of math, literacy, and the arts. For example, throughout the week, children used Engineering Design Journals (Figure 5) to plan, design, and refine their robotic constructions and programs. By using these journals, children were engaged in a combination of writing, dictating, and drawing. Children also grappled with math concepts of shapes, counting, and sequencing while building and programming their robots. Students exercised their creativity in designing their robots and creating displays using arts, crafts, and recyclable materials. Finally, songs and music were used to teach the steps of the engineering design process (see Appendix.) and the parts of a robot. The song was also performed during the Open House.



Figure 5: Engineering Design Journal

\section{Results}

\section{Robotics Projects}

Classroom observations and teacher interviews indicated that, by the end of the week, all groups of Pre-Kindergarten children ( $\mathrm{n}=37$ children, in 11 different groups) were able to create function- 
ing robots for a final project and demonstrate these projects during an Open House at the end of the week. By the last day of robotics, all groups' robots contained two motors, wheels, and a LEGO $^{\circledR}$ WeDo $^{\text {TM }}$ USB hub with wires correctly connected and securely attached. All robots also had a functional CHERP program by the end of the week. However, observations also indicated that each group received individualized help from an adult researcher (or their classroom teacher) during group building and programming time in order to ensure they had functional final projects.

\section{Knowledge of Engineers}

Classroom observations indicate that children had an increased understanding of what engineers do by the end of the week. Based on formal interviews with a subset of children $(n=23)$ at the end of the week, nearly half (47.8\%) described an engineer as someone who builds or designs things compared to only $32 \%$ at the beginning of the week. Some children were able to give detailed descriptions and provide examples of different objects made by engineers, while others simply said, "they build things". For example, one child responded, "Someone that builds something, like a robot, a car, an airplane, and a helicopter."

Prior to curriculum implementation, most children expressed they were only exposed to engineers as someone who drives a train. As one research assistant noted in their observations, when teachers attempted to introduce the concept of engineers, the children quickly became fixated on trains and it was initially difficult to expand their schema of an engineer.

\section{Knowledge of the Engineering Design Process}

In-class observations also showed children were able to identify the different steps of the Engineering Design Process, primarily when singing the Engineering Design Process song that was taught during the week (see Appendix). However, when formally interviewing a subset of children at the end of Robotics Week, only 3 (out of 23) were able to provide any of the steps. One student replied, "You ask a question and you imagine and you share and you test" while the other 2 students were able to provide all of the steps "Ask, Imagine, Plan, Create, Test \& Improve, Share". The remaining 20 students typically answered that they could not remember or did not know.

\section{Robotics and Programming Knowledge}

In a post survey, the Pre-Kindergarten classroom teachers were asked to rate on a scale from 1-5 how much their students learned about robotics ( 1 being nothing and 5 being a significant amount). All three teachers gave a score of 4 or 5 . On the same 1-5 scale, the teachers were also asked to rate how much their students learned about programming. Once again, all three teachers gave a score of 4 or 5 .

During curriculum implementation, all students were able to complete their final robotics projects and program their robots to perform a recycling related task. All robotic parts (motor, wires, hub, and computer) were connected correctly and all final programs were syntactically correct and allowed for either forward or backward movement across the classroom floor. When it came to programming their robots, one researcher observed that incorporation of the tangible programming blocks added to the absorption of the programming process, by creating a visual dimension that helped the students grapple with abstract concepts.

For most of the groups, completing the final project required a significant amount of individualized teacher attention. While most students were generally engaged in freely exploring their robots (without direct help), when it came to working on the specific task of choosing instructions that would allow their robot to help push or carry recyclables, the participants had more difficulty staying focused and troubleshooting errors in their programs. It was observed that children were 
not able to go through the stages of the Engineering Design Process in order to refine and improve their projects without direct help from the teacher. Most students were happy with whatever actions their robot performed, whether or not it was what they planned or directly solving the assigned task of creating a robot capable of "recycling".

Subsets of children were interviewed at the end of Robotics Week to understand their concept of robots. Responses to this question were varied between children. Four children were able to describe a robot as a machine. For example, one child responded that, "a robot is a machine that moves". Four children described a robot as something that can move according to the CHERP programming instructions they learned. For example, one child responded that a robot "goes forward, backward, spin, turn, and stops". Two children associated robots with their Robot Recyclers projects and answered that a robot helps with recycling. The remaining participants gave answers that did not fit with standard definitions or ideas of robots (i.e., "A robot is a Thomas train").

\section{Math and Literacy}

Observational data from researchers as well as the Pre-Kindergarten classroom teachers indicate that the robotics week curriculum engaged participating students in math and literacy in a variety of ways. All three of the Pre-Kindergarten teachers cited the design journals as a successful tool for integrating and practicing foundational literacy concepts during robotics time. In a postsurvey, one teacher explained, "The children used a combination of drawing and beginning writing to describe their experiences in their robotics journal." Figure 6 is an example of how a PreKindergarten child used a combination of drawing and early writing in their Engineering Design Journal to document the programming blocks needed to help their robot "recycle"



Figure 6: Sample Design Journal Page from a Pre-K Student
In the teacher post-surveys, two of the three Pre-K teachers described their observations of their class practicing foundational math skills during the robotics work. In a post-survey, one teacher wrote, "The children had to identify shapes (in pictures and structures), think logically (programming) and count (how many times did they want their robot to perform an action)". Researchers' field notes further describe observations of the regular inclusion of early math skills into the robotics lessons and that the robotics work stimulated students' interest in math. Observations described the children as engaged in counting and estimating when determining how far they wanted their robot to travel. According to both researchers and teachers, the children enjoyed freely building with Legos and grappling with the shapes and sizes needed to meet the design requirements of the Robot Recycler.

\section{Discussion}

The results of this study provide support of prior research stating that young children can build and program simple robots and that there are many benefits of integrating robotic technologies into the early childhood classroom in developmentally appropriate ways (Bers, 2008, 2010; Bers 
et al, 2002; Rogers \& Portsmore, 2004). Specifically, this study provides some evidence that PreKindergarten children can design, build, and program a robot designed to perform a specific task (in this case, recycling). After just one week of intense robotics work, all the children in this study (with the help of teachers and researchers) were able to create functioning robots for a final project and demonstrate these projects at an Open House. In line with Vygotsky's (1978) work on scaffolding, the structured guidance of classroom teachers and researchers were pivotal to the students' learning and achievement of curricular goals. Finally, the results of this study also indicate that integrating robotics into the regular schedule of a Pre-Kindergarten classroom does not necessarily require teachers to take time away from other foundational content. Instead, robotics can be used as a tool to allow children to grapple with math concepts, practice early literacy skills, and engage in the arts.

However, this study also highlights the difficulties and challenges that must be taken into account before implementing a robotics curriculum into a Pre-Kindergarten classroom. As compared to previous work on robotics with Kindergarten and older students (i.e., Bers 2010), the PreKindergarten children in this study covered fewer robotics and programming concepts and required a great deal of one-on-one help from adults. Research suggests that with new technologies and digital manipulatives, young children are capable of exploring concepts that were previously considered too advanced for them (Resnick et al., 1998). However, the results from this study suggest that for very young children, mastering these new concepts may require significant scaffolding and teacher attention. For example, in order for all groups in this study to have functioning robotics projects by the end of the week, each group required individualized assistance from a grown-up during all of the building and programming time. The students in this study had the benefit of their classroom teachers, researchers, and student volunteers in the classroom assisting with Robotics Week, resulting in an approximately 4:1 student to adult ratio, on average. In classes where fewer adults are present, modifications to the scope of the curriculum may be necessary. Additionally, this curriculum moved at a fast pace due to the time constraints of Robotics Week. In future iterations of the curriculum, it may be beneficial to expand the length of time devoted to each lesson, increase the amount of free-play time, and move more slowly through the curriculum in order to ensure that younger learners have a full understanding of each concept covered.

Introducing the concept of engineering to the Pre-Kindergarten children presented additional challenges that were not observed when implementing similar curriculum with older children. In particular, the teachers in this study expressed difficulty expanding the students' schema of what an engineer is (beyond someone who drives trains) and to foster an understanding of the Engineering Design Process and how it can be applied. Thus, expanding and strategically spacing the engineering lessons may be beneficial in the development of future curriculum for PreKindergarten students. Despite these difficulties, in-class observations showed children were able to identify the different steps of the Engineering Design Process, primarily when singing and music was used. They were able, in some capacity, to apply engineering concepts to building of their own robotics creations, as evidenced by their finished products. Still, 20 students could not recall the Engineering Design Process in post-test interviews. This suggests that although the young children in this study may have had difficulty verbalizing and remembering engineering concepts, they were generally able to apply these ideas during the lessons themselves. Different assessment techniques may be needed for use with Pre-Kindergarten students in future iterations of this study.

The Robotics Week curriculum was designed to be aligned with the Common Core Standards (NYSED, 2011). Within these standards for Pre-Kindergarten, there are several benchmarks for technology education, including using computers for writing, drawing and exploration; as well as learning to use technological tools independently (NYSED, 2011). Preliminary results from this 
study, primarily the classroom observations and teacher surveys, demonstrate that a robotics and programming curriculum can be used to successfully address these Common Core standards. Children were engaged in freely exploring the robotics and programming materials and used these to create personally meaningful digital projects.

\section{Limitations}

The limitations of this study are those that come with working in classrooms. Several parents opted their children out of our research study and/or did not return permission slips despite several attempts at collection; therefore, we were unable to collect data on those children for this paper. As such, our sample size is not representative, by number, of three Pre-Kindergarten classrooms at the school. In addition, due to the nature of the work within the classroom, we were allotted limited time to carry out pre-test and post-test interviews, which were also interrupted by activities such as nap and snack. If a child was absent during pre- and/or post-testing time, he or she could not be included in analysis.

This study is comprised primarily of observational and interview data collected with the goal of exploring a group of Pre-Kindergarten students' and teachers' work with a robotics and computer programming curriculum that had been iteratively tested within kindergarten classrooms (Bers, 2010; Bers \& Horn, 2010; Kazakoff \& Bers, 2012). The study was intended to be exploratory and, therefore, was limited in the amount and type data collected. Since the classroom observations employed were unstructured (i.e., researchers were not coding for specific behaviors), the objectivity and generalizability of some findings may also be limited in this first pilot study.

\section{Future Research}

This study looked only at preliminary qualitative and quantitative findings on incorporating robotics technology into Pre-Kindergarten classrooms. Many of the suggestions received by the classroom teachers and researchers' field notes are currently being incorporated into new iterations of Pre-Kindergarten robotics curriculum. As a part of the Ready for Robotics project, early childhood teachers (Pre-Kindergarten through $2^{\text {nd }}$ grade) from across the country will be systematically implementing a robotics curriculum and documenting this experience over the course of a whole school year. A combination of qualitative and quantitative assessments will be collected from both teachers and students in order to expand upon the findings presented here and inform best practices for incorporating robotics into Pre-Kindergarten classrooms.

\section{Conclusion}

Robotics offers young children and teachers a new and exciting way to tangibly interact with traditional early childhood curricular themes. This study demonstrates that it is possible to teach Pre-Kindergarten children to program a robot with developmentally appropriate tools, and, in the process, children may not only learn about technology and engineering, but also practice foundational math, literacy, and arts concepts. While there are many challenges to overcome when implementing robotics in a busy Pre-Kindergarten classroom, our work provides preliminary evidence that teaching young children about and through computer programming and robotics using developmentally appropriate tools may be a powerful tool for educating children across multiple domains. 


\section{References}

Barron, B., Cayton-Hodges, G., Bofferding, L., Copple, C., Darling-Hammond, L., \& Levine, M. (2011). Take a giant step: A blueprint for teaching children in a digital age. New York, NY: The Joan Ganz Cooney Center.

Bers, M. U. (2006). The role of new technologies to foster positive youth development. Applied Developmental Science, 10(4), 200-219.

Bers, M. U. (2008). Blocks to robots: Learning with technology in the early childhood classroom. NY: Teacher's College Press.

Bers, M. U. (2010). The TangibleK robotics program: Applied computational thinking for young children. Early Childhood Research and Practice, 12(2).

Bers, M. U. (2012). Designing digital experiences for positive youth development: From playpen to playground. Cary, NC: Oxford.

Bers, M. U., \& Horn, M. (2010). Tangible programming in early childhood: Revisiting developmental assumptions through new technologies. In I. Berson \& M. Berson (Eds.), High-tech tots: Childhood in a digital world. Global child advocacy series (pp. 49-70). Greenwich, CT: Information Age Publishing.

Bers, M. U., Ponte, I., Juelich, K., Viera, A., \& Schenker, J. (2002). Teachers as designers: Integrating robotics into early childhood education. Information Technology in Childhood Education, 123-145.

Brosterman, N. (1997). Inventing kindergarten. New York: H.N. Abrams.

Cejka, E., Rogers, C., \& Portsmore, M. (2006). Kindergarten robotics: Using robotics to motivate math, science, and engineering literacy in elementary school. International Journal of Engineering Education, 22(4), 711-722.

Clements, D. H. (1999). Young children and technology. In Dialogue on Early Childhood Science, Mathematics, and Technology Education. Washington, DC: American Association for the Advancement of Science.

Clements, D. H. (2002). Computers in early childhood mathematics. Contemporary Issues in Early Childhood, 3(2), 160-181.

Cunha, F., \& Heckman, J. (2007). The technology of skill formation. American Economic Review, 97(2), $31-47$.

Engage NY. (2011). New York State common core standards for ELA. Retrieved from http://www.p12.nysed.gov/ciai/common_core_standards/pdfdocs/p12_common_core_learning_standar ds ela.pdf

Highfield, K. (2010). Robotic toys as a catalyst for mathematical problem solving. Australian Primary Mathematics Classroom, 15(2), 22-27.

ISTE (International Society for Technology in Education). (2007). NETS for Students 2007 Profiles. Washington, DC: ISTE. Retrieved from www.iste.org/standards/nets-for-students/nets-for-students-2007profiles.aspx\#PK-2

Kazakoff, E., \& Bers, M. (2012). Programming in a robotics context in the kindergarten classroom: The impact on sequencing skills. Journal of Educational Multimedia and Hypermedia, 21(4), 371-391.

Kazakoff, E., Sullivan, A., \& Bers, M. (2013). The effect of a classroom-based intensive robotics and programming workshop on sequencing ability in early childhood. Early Childhood Education Journal, 41(4), 245-255

Kozima, H., Michalowski, M. P., \& Nakagawa, C. (2009). Keepon: A playful robot for research, therapy, and entertainment. International Journal of Social Robotics, 1(1), 3-18.

Lee, I., Martin, F., Denner, J., Coulter, B., Allan, W., Erickson, J.,...Werner, L. (2011). Computational thinking for youth in practice. ACM Inroads, 2(1), 32-37. 
MA DOE. (2011a). Massachusetts Curriculum Framework for English Language Arts and Literacy. Retrieved from http://www.doe.mass.edu/frameworks/ela/0311.pdf

MA DOE. (2011b). Massachusetts Curriculum Framework for Mathematics. Retrieved from http://www.doe.mass.edu/frameworks/math/0311.pdf

Madill, H., Campbell, R. G., Cullen, D. M., Armour, M .A., Einsiedel, A. A., Ciccocioppo, A. L.,...Coffin, W. L. (2007). Developing career commitment in STEM-related fields: Myth versus reality. In R. J. Burke, M. C. Mattis, \& E. Elgar (Eds.), Women and minorities in science, technology, engineering and mathematics: Upping the numbers (pp. 210 - 244). Northhampton, MA: Edward Elgar Publishing.

Markert, L. R. (1996). Gender related to success in science and technology. The Journal of Technology Studies, 22(2), 21-29.

Metz, S. S. (2007). Attracting the engineering of 2020 today. In R. J. Burke, M. C. Mattis. \& E. Elgar (Eds.) Women and minorities in science, technology, engineering and mathematics: Upping the numbers (pp. 184-209). Northampton, MA: Edward Elgar Publishing.

Mioduser, D., \& Levy, S. (2010). Making sense by building sense: Kindergarten children's construction and understanding of adaptive robot behaviors. International Journal of Computers for Mathematical Learning 15(2), 99-127.

National Association for the Education of Young Children (NAEYC) \& Fred Rogers Center. (2012). Technology and interactive media as tools in early childhood programs serving children from birth through age 8. Retrieved from http://www.naeyc.org/files/naeyc/file/positions/PS_technology_WEB2.pdf

NYSED. (2011). New York State prekindergarten foundation for the common core. Retrieved from: http://www.p12.nysed.gov/ciai/common_core_standards/pdfdocs/nyslsprek.pdf

Papert, S. (1980). Mindstorms: Children, computers, and powerful ideas. New York, NY: Basic Books.

Perlman, R. (1976). Using computer technology to provide a creative learning environment for preschool children. Logo memo no 24, Cambridge, MA: MIT Artificial Intelligence Laboratory Publications 260.

Piaget, J. (1977). The development of thought: Equilibrium of cognitive structures. New York, NY: Viking Press.

Resnick, M. (2006). Computer as paintbrush: Technology, play, and the creative society. In D. Singer, R. Golikoff, \& K. Hirsh-Pasek (Eds.), Play = learning: How play motivates and enhances children's cognitive and social-emotional growth. New York, NT: Oxford University Press.

Resnick, M., Maloney, J., Monroy-Hernandez, A., Rusk, N., Eastmond, E., Brennan, K., \& Kafai, Y. (2009). Scratch: Programming for All. Communications of the ACM, 52(11), 60-67.

Resnick, M., Martin, F., Berg, R., Borovoy, R., Colella, V., Kramer, K., \& Silverman, B. (1998). Digital manipulatives: New toys to think with. In Proceedings of the ACM Conference on Human Factors in Computing Systems CHI '98 (pp. 281-287), Los Angeles, CA: ACM Press.

Reynolds, A. J., Temple, J. A., Ou, S. R., Arteaga, I. A., \& White, B. A. B. (2011). School-based early childhood education and age-28 well-being: Effects by timing, dosage, and subgroups. Science, 333(6040), 360-364. DOI:10.1126/science.1203618, Retrieved from http://www.sciencemag.org/content/333/6040/360.full

Rogers, C., \& Portsmore, M. (2004). Bringing engineering to elementary school. Journal of STEM Education, 5(3-4), 14-28.

Rogoff, B. (2003). The cultural nature of human development. New York: Oxford University Press.

Rogoff, B., Goodman Turkanis, C., \& Bartlett, L. (2001). Learning together: Children and adults in a school community. New York, NY: Oxford University Press.

Sarama, J., \& Clements, D. H. (2003). Building blocks of early childhood mathematics. Teaching Children Mathematics, 9, 480-484.

Siegler, R. S. (1998). Children's thinking(3rd ed.). Upper Saddle River, NJ: Prentice Hall. 
Steele, C. M. (1997). A threat in the air: How stereotypes shape intellectual identity and performance. American Psychologist, 52, 613-629.

Stiehl, W. D., Chang, A., Wistort, R., \& Breazeal, C. (2009). The robotic preschool of the future: New technologies. Proceedings of Interaction Design for Children, June 3-5, 2009, in Como, Italy.

Sullivan, A., \& Bers, M. U. (2012). Gender differences in kindergarteners' robotics and programming achievement. International Journal of Technology and Design Education. DOI: 10.1007/s10798-0129210-z. Online First.

Svensson, A. (2000). Computers in school: Socially isolating or a tool to promote collaboration? Journal of Educational Computing Research, 22(4), 437-453.

Wartella, E., \& Jennings, N. (2000). Children and computers: New technology - Old concerns. Children and Computer Technology, 10(2), 31-43.

Wyeth, P. (2008). How young children learn to program with sensor, action, and logic blocks. International Journal of the Learning Sciences, 17(4), 517-550.

U.S. Department of Education. (2010a). Educate to innovate. Retrieved from http://www.whitehouse.gov/issues/education/educate-innovate

U.S. Department of Education. (2010b). Transforming American education: Learning powered by technology. Washington, D.C. Retrieved from: http://www.ed.gov/technology/netp-2010

Vygotsky, L.S. (1978). Mind in society. Cambridge, MA: Harvard University Press.

Zelazo, P. D., Carter, A., Reznick, J. S., \& Frye, D. (1997). Early development of executive function: A problem-solving framework. Review of General Psychology, 1(2), 198-226.

\section{Appendix}

Songs Used to Reinforce Engineering and Robotics Concepts

\section{The Engineering Design Process Song}

We ask and imagine,

We plan and create,

We test and improve,

And then we share!

\section{The Robot Parts Song (to the tune of "Dry Bones")}

The motor is connected to the, wire.

The wire is connected to the, hub.

The hub is connected to the, computer.

So, move, robot, move! 


\section{Biographies}

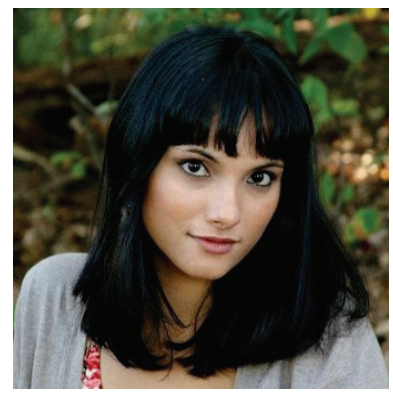

Amanda Sullivan is a doctoral student working with the DevTech Research Group at the Eliot-Pearson Department of Child Development at Tufts University. She holds a B.A. in Psychology and an M.A. in Child Development. Amanda's research interests broadly examine the role of new technologies and media in the lives of children. Her current work focuses on best practices for integrating robotics and computer programming into early childhood education.

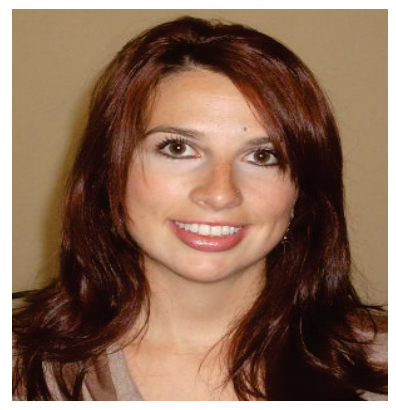

Elizabeth R. Kazakoff is a doctoral student working with the DevTech Research Group at the Eliot-Pearson Department of Child Development at Tufts University. She holds a B.S. and M.Ed. in psychology. Elizabeth's broad research interests focus on how new technologies impact early childhood development, especially interactive robotics and programming tools. Her dissertation work focuses specifically on the interplay between self-regulation and learning to code.

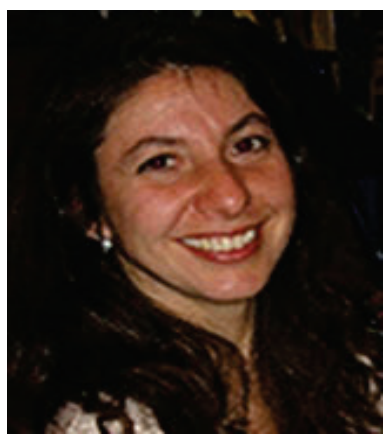

Marina Umaschi Bers is a professor at the Eliot-Pearson Department of Child Development and the Computer Science Department at Tufts University. She heads the interdisciplinary Developmental Technologies research group which focuses on designing and studying innovative learning technologies to promote positive youth development. Dr. Bers received prestigious awards and has written two books "Blocks to Robots: Learning with Technology in the Early Childhood Classroom" (2008; Teacher's College Press) and "Designing Digital Experiences for Positive Youth Development: From Playpen to Playground" (2012; Oxford University Press). Dr. Bers has an M Ed from Boston University and an MS and PhD from the MIT Media Lab. More on Dr. Bers:

http://www.tufts.edu/ mbers01/ 